\title{
MECHANICAL BEHAVIOR OF THREE-DIMENSIONAL NAILING PLATES JOINTS: EXPERIMENT AND NUMERICAL DESIGN
}

\author{
Mustapha TAAZOUNT ${ }^{1}$ and Abdelhamid BOUCHAÏR ${ }^{2}$ \\ ${ }^{1}$ Laboratoire de Mécanique Ingénierie (LaMI), Polytech'Clermont, Blaise Pascal University, BP 206 - 63174 \\ AUBIERE (France) \\ E-mail: mustapha.taazount@polytech.univ-bpclermont.fr \\ ${ }^{2}$ Laboratoire de Mécanique Ingénierie (LaMI), Polytech'Clermont, Blaise Pascal University, BP 206 - 63174 \\ AUBIERE (France) \\ E-mail: Abdelhamid.bouchair@polytech.univ-bpclermont.fr
}

\begin{abstract}
The aim of this study is to characterize the mechanical behavior of connections timber-to-timber joist hangers with specific nail fasteners. The methodology proposed by technical design standards is based on the hypothesis of an elastic and linear joint behavior. However, the local behavior of joint is semirigid characterized by the ductility of wood material in embedment and the non linear behavior of the nail fasteners in bending. Hence, in this study, the combination of a comprehensive experimental setup and a numerical approach is developed to analyze the evolution of the forces in the joint. Firstly, various tests are realized on specific nail fasteners, using different glulam species, in accordance with European test standards. They concern the withdrawal push-out test, the single plane shear and the yield bending moment. Besides, the adequacy of the methodology proposed by Eurocode 5 for dowel-type fasteners is discussed. Secondly, a similar investigation is carried out on a whole timber-to-timber joint, with nailed tridimensional metal plates. Considering the hypothesis of a semi-rigid behavior of the joint, the stiffness of each fastener is identified in tension and shear slips. Finally, a finite element model is applied and discussed considering the fasteners represented by bi-directional mechanical springs. The stiffness of each spring is considered as the slip modulus of each fastener defined by tests. A semi-rigid formulation was adopted and the overall joint behavior is apprehended numerically.
\end{abstract}

Key Words : wood, joist hanger, three-dimensional metal plates, fasteners, nails, semi-rigidity

\section{INTRODUCTION}

In timber structural design, the joint areas have major importance on strength and durability of structures. An inadequate design is responsible of many pathologies influencing the mechanical behavior of timber structures. This concerns mainly the stiffness that plays a crucial role in stress distribution in the structure.

This study is devoted to timber-to-timber joints using three dimensional metal plates (joist hangers). This is the case of secondary beam (joist), supporting floor for example, mounted on wooden support (main beam or column) through threedimensional nailing metal plates. This technology is often used in achieving light floors (wood and concrete) and in building rehabilitation, mainly for indoor applications.

This timber-to-timber connection combines the behavior of wood, steel plates and steel fasteners. Thus, the complexity of their behavior, due to the associa- tion of various materials, needs local and global analysis to define analytical approaches to be used in practical design of structures. In local scale, the analysis concerns the load-carrying capacity of the elementary joints, with one fastener, considering the withdrawal, the shear and the bending yield moment of one fastener isolated or in the joint. The results of the local approach, based on tests, are used in the global analysis. The global analysis takes into account the mechanical interactions between different components of the joint (timber, member, fasteners and metal plate). In the structural analysis, the joints with mechanical fasteners are usually considered as either pinned or rigid. The real behavior is usually semi-rigid with linear or nonlinear character. Thus, the local behavior of the joints may have an important influence on the internal force distribution within statically undetermined timber structures.

In this study, four parts are considered. The first part concerns the experimental characterization of the 
fasteners. The second part is dedicated to the experimental analysis of the timber-to-timber Three Dimensional Nailing Plates "TDNP" joint. The third part concerns the experimental identification of the slip modulus of nails. The fourth part concerns the proposal of a finite element modeling in view of optimizing the various components of the joint.

Thus, a short exposure is given about the state of the art of the hanger joints behavior and design. Then, the joint components used in the different tests (and push-out tests) on the nail fasteners are presented. The tests were performed according to European standards (prEN 409, prEN 14591, prEN 1382, prEN 1380) and Eurocode 5 (EC5) ${ }^{1)}$. They are performed to obtain the characteristic load-carrying capacity values of the mechanical parameters characterizing the behavior of the nail fasteners in the hanger joint, with constant diameter $d$ and for different lengths $l_{p}$. These parameters are the withdrawal capacity $F_{a x, R k}$, the load-carrying capacity per shear plane per fastener $F_{v, R k}$, the yield moment of the nail $M_{y, R k}$. Similar studies have been conducted on other types of nail fasteners in 2) and 3). In 2), the results of experimental studies on stainless steel nails are presented and in 3), the study is limited to the characterization of nails in spruce member. The number of specimens, by category of nails, is at least equal to five. Using a statistical analysis, the studies showed that the equations proposed by Eurocode 5 may induce a large error, especially on the withdrawal capacity. Also, a comparison was made between the experimental and the design values of the EC5. The experimental results were adjusted and used in the rest of the study.

The experimental study of the member-to-member joint (joist and beam) is presented. It is accomplished according to the European standards ETAG015, EOTA-TR015, TR016-EOTA and Eurocode 5 ${ }^{1)}$. The number of five specimens for each joint type is adopted. The forces, displacements and rotations are measured and saved using an experimental device managed by a computer system. A statistical study is made to evaluate the upper and lower characteristic mean values using $\mathrm{t}$-student statistical tables.

The structural analysis of timber structures may be very complex, especially when nonlinearity is taken into account. In general, with the absence of appropriate models covering the behavior of the joints, researchers proceed by testing ${ }^{4), 5), 6), 7)}$. Thus, a part of this study is dedicated to discuss and analyze the validity of the design calculation methods is checked by the comparison of their resistance with that given by tests. The analytical models are based on Eurocode $5^{1)}$, for the withdrawal capacity, in combination with the Johansen's theory ${ }^{8}$, for the loading shear capacity of the nails. To define the loads applied on the nails in a real configuration of joint, the modeling of the semi-rigid behavior of the joint is considered. This semi-rigid character is described by two springs. One global spring represents the moment-rotation relationship and the other one represents the relationship between the reaction force and the vertical slip in the joint, at the end of the connected beam. The stiffness of these global springs is identified using the experimental results.

From the tests, the axial and the transversal slip modulus of the fasteners are obtained. They are used in the finite element model where each fastener is characterized by springs with bidirectional imposed stiffness representing the withdrawal and the slip (shear) behavior. One tested joint is modeled and the numerical results showed a very good agreement with the experimental ones. It should be noted that these calculations were carried out using "Cosmos" "FEM" code. The contact between member and the bottom of metal plate was considered through bilinear elastic mechanical behavior.

In this model dedicated to the analysis of the semirigid behavior of the joint, the compressive strength in the direction perpendicular to grain and shear strength of wood in the contact area with bottom of "TDNP" are not considered. This numerical approach, with the limited number of tests, gives the possibility to analyze various geometrical configurations of joints with a view of developing a simple and practical design approach for this kind of joints. Another advantage of the finite element model is that it gives the distribution of stress in the joint components that can be used as complementary information in the optimization of the joint dimensions and geometries.

\section{EXPERIMENTAL DESIGN AND OB- JECTIVE}

This study is focused on the analysis of the behavior of member-to-member three-dimensional nailing metal plate. This technological device is used in civil engineering to connect the timber members (joists or beams) supporting the floors or the roofs. The supports of the joints (beams, columns or walls) can be made by various materials: wood, concrete or steel. The study is focused particularly on the "TDNP"support nail fasteners on both sides: at front and side of the connected joist. The front side is attached to the support member and the lateral side is fixed to the connected (supported) member. Thus, the forces are transferred, from the secondary members through nail plates to the support members (Fig. 1 (a)).

As the approach proposed by Eurocode $5^{1)}$ to study the hanger joints, it is recommended to proceed by mechanical testing; an experimental program is defined using nailed joint. The tests are conducted ac- 


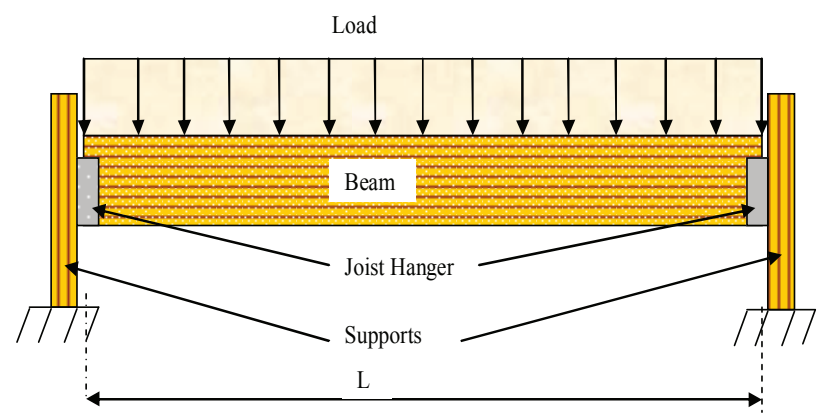

(a)

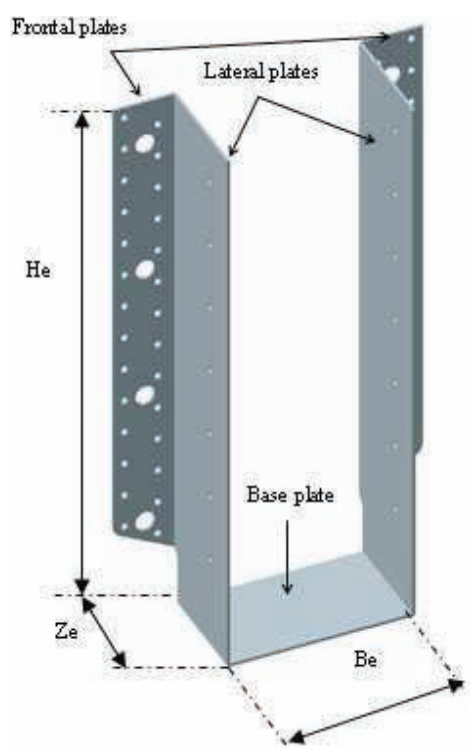

(b)

Fig. 1 Members and fasteners description.

cording to the European standards. The members used are made of wood GL24h class according to EN 1194. The joist hangers (TDNP) (Fig. 1 (b)) are made of galvanized steel sheet of grade DX 51D with 2 or 4 mm thickness according to NF EN 10142. The TDNP is connected to members (joist and support) using ring thread nails (Fig. 1 (c)) with diameter $d=3.8 \mathrm{~mm}$ and lengths $l_{p}$ ranging from 30 to $60 \mathrm{~mm}$. The use of such nails fasteners is justified by their high withdrawal strength.

In the experimental program, local and global tests are made. The local tests concern the nails fasteners in tension (axial withdrawal resistance), in shear combined with bending (shear resistance) or in pure bending (yield moment). The global tests are made with real connections between timber members using "TDNP" joints. The nails in the global test behave in a combination of tension, shear and bending.

\section{(1) Nail fasteners tests}

According to $\mathrm{EC} 5^{1)}$, the nominal diameter $d$ of nail should not be less than $1.9 \mathrm{~mm}$ and not greater than 8 $\mathrm{mm}$. Section of the nail head should be greater than $2.5 d^{2}$ and the head thickness $h_{t}$, must be greater than

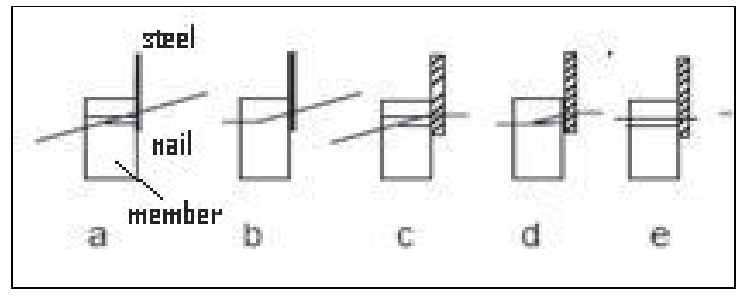

Fig. 2 Failure modes for steel-to-timber connections (EC5).

$0.25 d$. Dimensional tolerances for nails must be in accordance with European standard EN 10230-1.

Under axial loads, the nail fasteners joints exhibit a brittle behavior depending on the shape of the nail shank. The axial withdrawal capacity depends on the friction between the nail and the member, the contact area (smooth nails, ringed nails) plays an important mechanical role. Furthermore, the behavior of nailed joints depends also on other parameters such as moisture content, wood density and pointside penetration length. When nails are embedded in dense wood, there is a risk that excessive splitting occurs. To limit this risk, one solution is to pre-drill the wood. In this case, the pre-drilled diameter is less than or equal to $80 \%$ of the nail diameter.

The design method for dowel-type fasteners timber connections proposed by Eurocode $5^{1)}$ is based on Jahansen's yield theory ${ }^{8)}$. The load-carrying capacity characteristic for nails, in simple shear, depends on the thickness of the metal plate. In our case, the nail diameter is small compared to the steel plate thickness. So, the formulae for thick metal plates are used $(\text { Eqs. }(1))^{1)}$. These equations correspond to different failure modes of a steel-totimber connection in simple shear as shown in Fig. 2.

$F_{v, R k}=\min \left\{\begin{array}{l}f_{h, k} t_{l} d\left[\sqrt{2+\frac{4 M_{y, R k}}{f_{h, k} d t_{1}^{2}}-1}\right]+\alpha_{c} F_{a x, R k}(\mathrm{c}) \\ 23 \sqrt{M_{y, R k} f_{h, k} f_{h, k} d}+\alpha_{c} F_{a x, R k} \\ f_{h, k} t_{1} d\end{array}\right.$

where:

$F_{v, R k}$ : the characteristic load-carrying capacity per shear plane per fastener

$f_{h, k}$ : the characteristic embedment strength in the timber member

$t_{1}$ : the timber thickness per penetration depth

$d:$ the fastener diameter

$M_{y, R k}:$ the characteristic fastener yield moment

$F_{a x, R k}$ : the characteristic withdrawal capacity of the fastener

$\alpha_{c}$ : the contribution coefficient of the loadcarrying capacity due to the rope effect $\left(0 \leq \alpha_{c} \leq\right.$ 1) 
According to EC5, for nails without predrilled holes and loaded laterally, the characteristic values for the embedding strength, depends on the fastener diameter and the member density (Eq.(2) $)^{1)}$. In this equation, $\rho_{k}$ is the characteristic member density $\left(\mathrm{kg} / \mathrm{m}^{3}\right)$, and $d$ is the nail diameter.

$$
f_{h, k}=0.082 \rho_{k} d^{-0.3}
$$

In structural design, the bending capacity of fastener (yield moment) is given by Eq.(3) ${ }^{12), 1)}$. In this equation, $f_{u}$ is the tensile strength of the wire $\left(\mathrm{N} / \mathrm{mm}^{2}\right)$.

$$
M_{y, R k}=0.3 f_{u} d^{2.6}
$$

With particular nails, the Eq.(3) cannot be used and the characteristic value of the yield moment $M_{y, R k}$ is obtained by experimental approach, according to the procedure of the European standard EN 409, using experimental tests. The characteristic value $\left(M_{y, R k}=\right.$ $4893 \mathrm{~N} \cdot \mathrm{mm}$ ) is obtained from bending tests of ten specimens considering the fifth percentile value. It can be noted that these nails with circular sections can be installed without pre-drilling holes.

When nails are loaded axially, the withdrawal capacity, as defined in EN-14592 standard, is given by equation $(4)^{1)}$. Where $f_{a x, k}$ is the characteristic pointside withdrawal strength, $f_{\text {head, } k}$ is the characteristic headside pull-through strength; $t_{p e n}$ is the pointside penetration length or the length of the threaded part in the pointside member, $t$ is the thickness of the headside member and $d_{h}$ is the nail head diameter.

$$
F_{a x, R k}=\min \left(f_{\text {ax }, k} d t_{\text {pen }} ; f_{\text {head }, k} d_{h}^{2}\right)
$$

For connections under combination of axial $\left(F_{a x, E d}\right)$ and lateral $\left(F_{v, E d}\right)$ loads, Eq. $(5)^{1)}$ defined in EN 14592 standard should be used. In this equation, the parameters $F_{a x, R d}$ and $F_{v, R d}$ are the design loadcarrying capacities of the connection under axial and lateral load, respectively.

$$
\left(\frac{F_{a x, E d}}{F_{a x, R d}}\right)^{2}+\left(\frac{F_{v, E d}}{F_{v, R d}}\right)^{2} \leq 1
$$

The axial load-carrying capacity is given by the equation $(6)^{1)}$. The parameter $l$ is the pointside penetration length for smooth nails or the length of the threaded part in the pointside member for the non smooth nails. The design value of the withdrawal strength $f_{a x, R d}$ is obtained from its characteristic value $f_{a x, R k}$ given by an empirical expression (Eq. 7).

$$
\begin{gathered}
F_{a x, R d}=f_{a x, R d} d l \\
f_{a x, R k}=65 \times 10^{-6} \rho_{k}^{2}
\end{gathered}
$$

The design value of shear force per shear plane of fastener $F_{v, R d}$ is obtained taking into account the Kmod factor, representing the duration of loading and the moisture content, and $\gamma_{M}$ the partial safety factor.

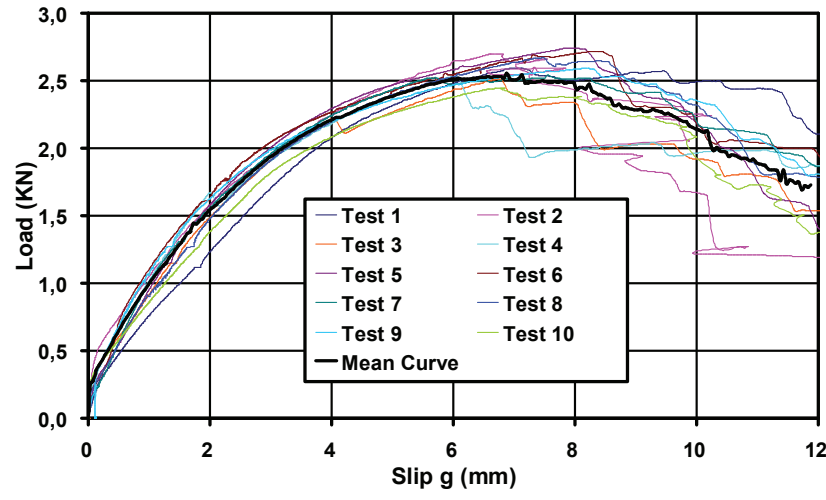

Fig. 3 Load - Slip curves (specimens with timber GL24h and $\left.l_{p}=50 \mathrm{~mm}\right)$.

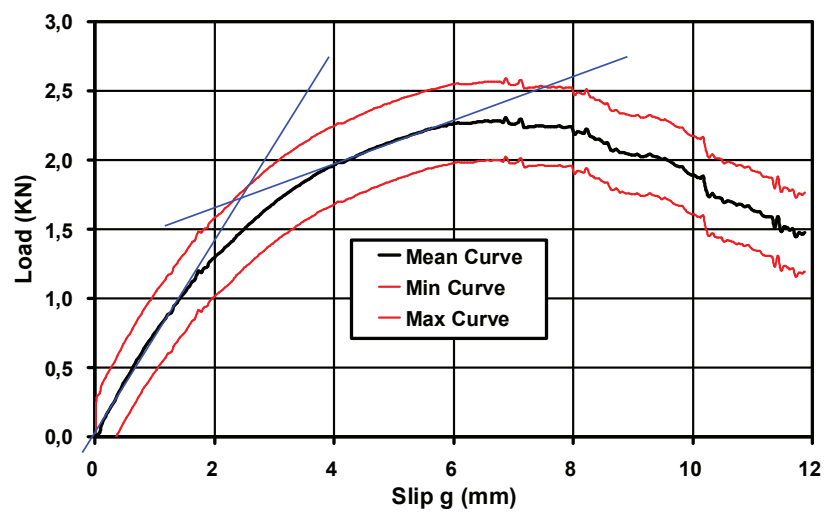

Fig. 4 Mean, Max and Min Load - Slip Curves (specimens with timber GL24h and $l_{p}=50 \mathrm{~mm}$ ).

Thus, the design value is given by the following equation: $F_{v, R d}=\left(K_{\bmod } / \gamma_{M}\right) F_{v, R k}$ (with: $K_{\text {mod }}=0.8$ and $\left.\gamma_{M}=1.25\right)$.

In this specific nail case, in order to compare the calculation and the experimental results, it was be necessary to proceed by mechanical push-out shear tests on nails with diameter $d=3.8 \mathrm{~mm}$ and lengths ranging from 30 to $60 \mathrm{~mm}$. For each length $l_{p}$ test series with ten specimens are performed. For each set of $l_{p}$ series tests, the upper and lower statistical mean values are obtained by a 5\% percentile statistical analysis using t-Student statistical tables. The mechanical tests are done using different classes of glulam member: GL20h, GL24h, GL28h and GL32h according to EN 1194 and EN 14080 standards. The measured average value of the wood moisture content ranges from $10 \%$ to $12 \%$ for the different members.

Fig. 3 and Fig. 4 show the load-slip curves for ten specimens of timber-to-timber connections in simple shear. This example of illustration concerns timber of a resistance class GL24h, ring threaded specific round nails with diameter $3.8 \mathrm{~mm}$ and length $l_{p}=50 \mathrm{~mm}$. Load on Fig. 3 and Fig. 4 is given per shear plane and per fastener. These tests concern a set of member 


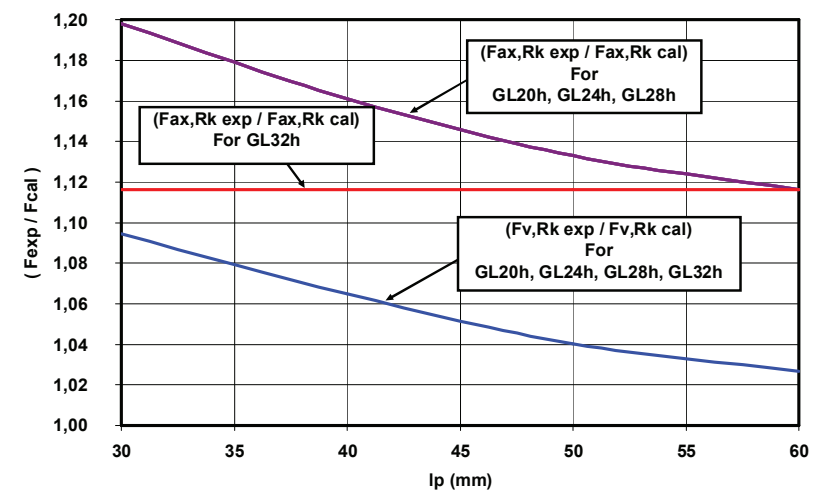

Fig. 5 Ratio of the experimental and calculated resistances versus the length $l_{p}$.

Table 1 Relative Error on $F_{a x, R K}$.

\begin{tabular}{c|c|c|c|c}
\hline$l_{p}(\mathrm{~mm})$ & GL20h & GL24h & GL28h & GL32h \\
\hline 30 & $20 \%$ & $20 \%$ & $20 \%$ & $12 \%$ \\
\hline 40 & $16 \%$ & $16 \%$ & $16 \%$ & $12 \%$ \\
\hline 50 & $13 \%$ & $13 \%$ & $13 \%$ & $12 \%$ \\
\hline 60 & $12 \%$ & $12 \%$ & $12 \%$ & $12 \%$ \\
\hline Mean Relative Error & $\mathbf{1 5 \%}$ & $\mathbf{1 5 \%}$ & $\mathbf{1 5 \%}$ & $\mathbf{1 2 \%}$ \\
\hline
\end{tabular}

joints with two nailing metal plates (thick plates ${ }^{1)}$ ). The nails are arranged symmetrically on either side of plates, and they were bolted on a rigid support. Tensile load is applied, as defined in EN 26891 "ESDT" (Fig. 8), on member until joint failure. Load and slip are measured using LVDT transducers fixed between member and plates.

However we note that the shear behaviour of nails is characterized by a linear behaviour followed by an elasto-plastic one, which can be represented by two linear lines as shown in Fig. 4.

The withdrawal tests are performed by a specialized laboratory according to EN 1382 standards using the same timber classes. The results of comparison between the calculated values, using the equation (7) for the load in tension and the equation (1) for the load in simple shear, and the experimental values are summarized in Fig. 5, where the $\left(F_{\text {experiment }} / F_{\text {calculated }}\right)$ ratio's are plotted. It should be noted that the formula (1) is used with rope effect equal to $15 \%\left(\alpha_{c}=\right.$ $0.15)^{1)}$.

Through these comparisons, it can be observed that the relative error between calculations and experiment is lower than $15 \%$ in withdrawal (Table 1) and 6\% in simple shear (Table 2). Therefore, the effect of variability between timber types is less sensitive in simple shear than in tension (withdrawal test) (Fig. 5). Also, for a dense wood GL32h, the error between calculation and experiment is less than those of GL20h, GL24h and GL28h specimens.
Table 2 Relative Error on $F_{v, R K}$.

\begin{tabular}{c|c|c|c|c}
\hline$l_{p}(\mathrm{~mm})$ & GL20h & GL24h & GL28h & GL32h \\
\hline 30 & $9 \%$ & $9 \%$ & $9 \%$ & $8 \%$ \\
\hline 40 & $6 \%$ & $6 \%$ & $6 \%$ & $6 \%$ \\
\hline 50 & $4 \%$ & $4 \%$ & $4 \%$ & $3 \%$ \\
\hline 60 & $3 \%$ & $3 \%$ & $2 \%$ & $2 \%$ \\
\hline Mean Relative Error & $\mathbf{6 \%}$ & $\mathbf{5 \%}$ & $\mathbf{5 \%}$ & $\mathbf{5 \%}$ \\
\hline
\end{tabular}

Table 3 Characteristic and Design values capacities fasteners (GL24h, $l_{p}=50 \mathrm{~mm}$ ).

\begin{tabular}{c|c|c|c}
\hline$F_{a x, R k}(\mathrm{kN})$ & $F_{v, R k}(\mathrm{kN})$ & $F_{a x, R d}(\mathrm{kN})$ & $F_{v, R d}(\mathrm{kN})$ \\
\hline 1.53 & 1.77 & 0.98 & 1.09 \\
\hline
\end{tabular}

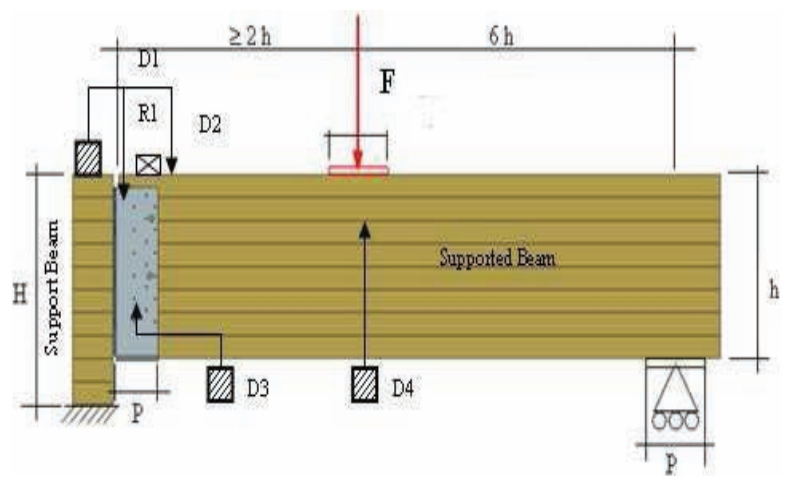

Fig. 6 Experimental setup scheme (ETAG-015).

In the remainder of this work, the experimental withdrawal curves are adjusted using the same formula as Eq.(7) $\left(f_{a x, R k}=\beta_{l p} \rho_{k}^{2}\right)$, where $\beta_{l p}$ depends on the nail length $l_{p}$. For the resistance in simple shear, Eq.(1) is used.

The main values of resistance in shear and withdrawal $\left(F_{v, R K}, F_{a x, R K}, F_{v, R d}\right.$, and $\left.F_{a x, R d}\right)$, to be used later, are given in Table 3 for $l_{p}=50 \mathrm{~mm}$ in timber member with resistance class GL24h.

\section{(2) Member-to-member joint tests}

The experimental setup used to study the memberto-member joint is showed in Fig. 6. The testing procedure is detailed in ETAG-015 standard. The members are made in glulam wood GL24h defined by EN 1194 "Glulam-class strength and determination of characteristic values" and EN 14080 standard. The connection between members and metal plate are made using nail fasteners defined in the previous section. For the connection between the timber member and the hanger joint plate, nine nails are used per side with length $l_{p}=30 \mathrm{~mm}$. For the connection between the hanger plate and the timber support, eighteen nails are used per side with $l_{p}=50 \mathrm{~mm}$. 


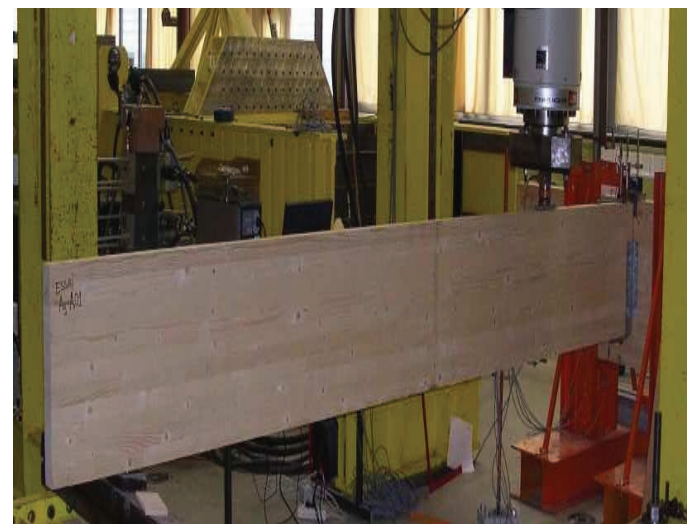

Fig. 7 Experimental setup.

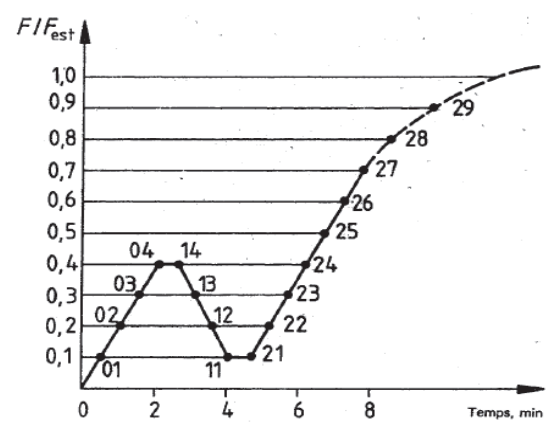

Fig. 8 Load-Time curve for tests (EN 26891).

The height of the three dimensional metal plate is proportional to the height of the timber connected member $\left(h_{\text {plate }} \leq 2 / 3 h_{\text {member }}\right)$. The dimensions used are: thickness $e=2 \mathrm{~mm}$, height $h_{e}=346 \mathrm{~mm}$, inside width of $72 \mathrm{~mm}$, total width of $152 \mathrm{~mm}$ and depth of $75 \mathrm{~mm}$. The distance between nails on the height of the metal plate are defined according to the recommendations of $\mathrm{EC} 5^{1)}$.

The load $F$ is applied at distance $2 h$ from the end of the member. The experimental setup is shown on Fig. 6. The transducer $D_{1}$ is used to measure the relative slip between the hanger plate and the supporting member. The transducer $D_{2}$ measures the relative slip between the supported and the supporting members. $D_{3}$ measures the displacement of the hanger plate bottom and $D_{4}$ measures the vertical displacement of the supported member under the location of the applied load. The inclinometer $R_{1}$ measures the rotation of the supported member. These tests were performed in accordance with the requirements of the various standards listed above.

Preliminary tests are performed to obtain the maximum load $F_{\text {est }}$. After that, the load is applied according to the graphic of Fig. $8(\mathrm{EN} \mathrm{26891)})^{1)}$.

The member dimensions are: $L \times h \times e=4000 \times$ $400 \times 70 \mathrm{~mm}^{3}$, with a free length of $l=3200 \mathrm{~mm}$. The support member is clamped rigidly at its base.

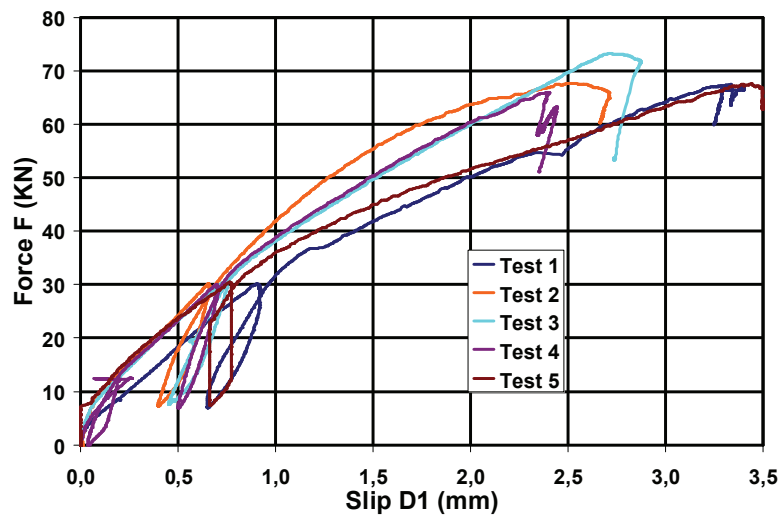

Fig. 9 Load - Slip curves $\left(F-D_{1}\right)$.

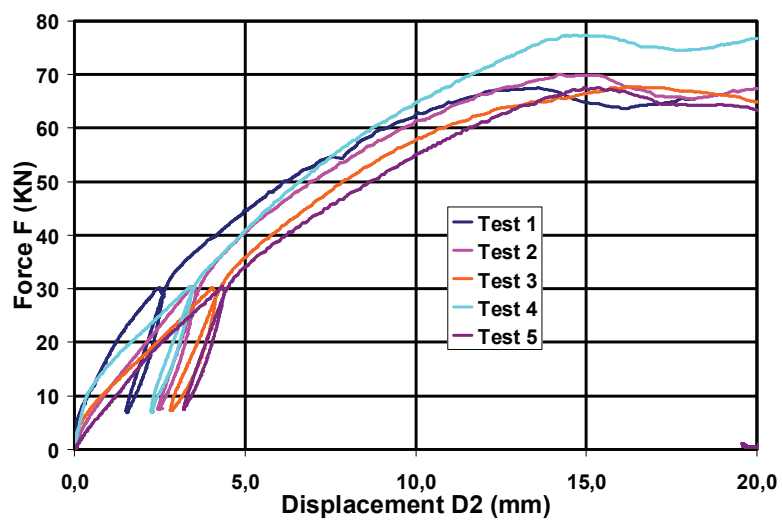

Fig. 10 Load - Displacement curves $\left(F-D_{2}\right)$.

The measured parameters $\left(F, D_{1}\right.$ and $\left.R_{1}\right)$ allow the characterization of the mechanical behavior of the member-support joint. However, nails are loaded with axial and lateral forces. The displacement $D_{2}$ represents the slip between the two connected timber members. So, it includes the displacement $D_{1}$ and the displacement of the supported member in the hanger. For this reason, the displacement $D_{2}$ is generally greater than $D_{1}$. The difference of displacement $\left(D_{2}-D_{1}\right)$ and the rotation $R_{1}$ characterizes the behavior of the connection between the joist (supported member) and the hanger. In this connection, the nails are loaded in shear. $D_{4}$ record gives the possibility to evaluate the bending deflection of the beam and the influence of the mechanical characteristics of the semi-rigid joint.

The tests are performed with controlled load up to $70 \%$ of the maximum estimated load. After that, the load is applied with displacement control. The test ends when the maximum load is reached or when slip $\left(D_{1}\right)$ is greater or equal to $15 \mathrm{~mm}$. The number of five specimens is performed for each series of tests.

Figs. 9, 10, 11 and 12 represent the evolution of the load $F(\mathrm{kN})$ versus the displacements $D_{1}, D_{2}, D_{4}$ and the rotation $R_{1}$, respectively (Fig. 6).

Based on the load-slip and the load-rotation curves 


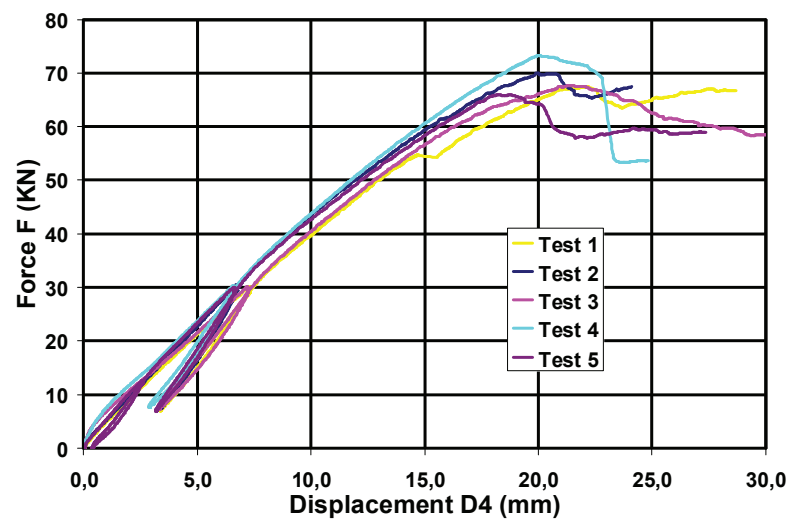

Fig. 11 Load - Displacement curves $\left(F-D_{4}\right)$.

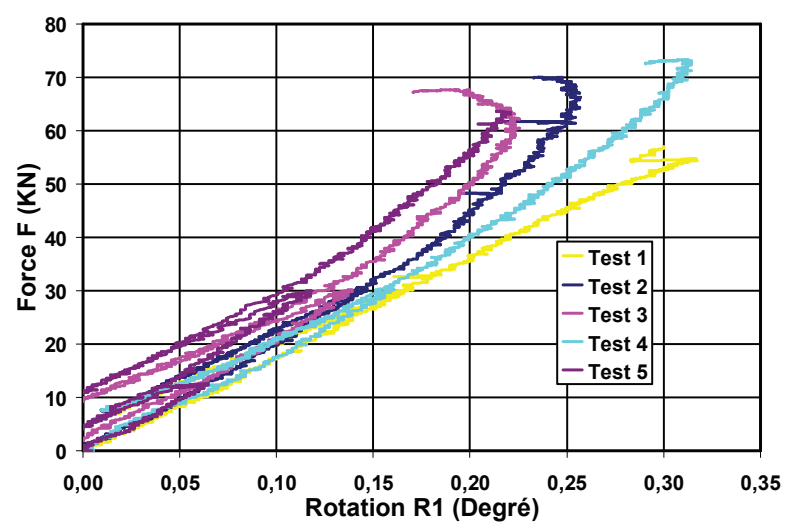

Fig. 12 Load - Rotation curves $\left(F-R_{1}\right)$.

Table 4 Statistical values (resistance, slip and rotation).

\begin{tabular}{|c|c|c|c|c|c|c|}
\hline & $\begin{array}{l}F_{\max } \\
(\mathbf{k N})\end{array}$ & $\begin{array}{c}D_{1} \\
(\mathbf{m m})\end{array}$ & $\begin{array}{c}D_{2} \\
(\mathbf{m m})\end{array}$ & $\begin{array}{c}\left(D_{2}-D_{1}\right) \\
(\mathrm{mm})\end{array}$ & \begin{tabular}{c|}
$D_{4}$ \\
$(\mathbf{m m})$
\end{tabular} & $\begin{array}{l}R_{1} \\
\left({ }^{\circ}\right)\end{array}$ \\
\hline $\begin{array}{l}\text { Estimate } \\
\text { Mean Value }\end{array}$ & 67 & 2.9 & 15.0 & 12.2 & 20.4 & 0.3 \\
\hline SD Value & 3.8 & 0.4 & 1.0 & 1.3 & 1.3 & 0.04 \\
\hline $\begin{array}{l}\text { Lower } \\
\text { Mean Value }\end{array}$ & \begin{tabular}{|l|l|}
58.8 \\
\end{tabular} & 2.0 & 12.9 & 9.4 & 17.7 & 0.2 \\
\hline $\begin{array}{l}\text { Upper } \\
\text { Mean Value }\end{array}$ & 75.1 & 3.8 & 17.2 & 14.9 & 17.2 & 0.4 \\
\hline
\end{tabular}

obtained from tests, different properties can be calculated including the mean and the standard deviation statistics of maximum load $\left(\bar{F}_{\max }, F_{\sigma \max }\right)$ and the upper and the lower estimate mean values with $5 \%$ percentile statistic (Table 4).

The average moisture content of the members is $12 \%$ and the average density of the support beams is $413 \mathrm{~kg} / \mathrm{m}^{3}$ and that of the connected members is 405 $\mathrm{kg} / \mathrm{m}^{3}$. The observed modes are mainly withdrawal and shear failures of the nails.

It can be observed that the characteristic mean value of maximum load is $59 \mathrm{kN}$ corresponding to a slip $D_{1}$ of $2 \mathrm{~mm}$ (Table 4), a relative displacement

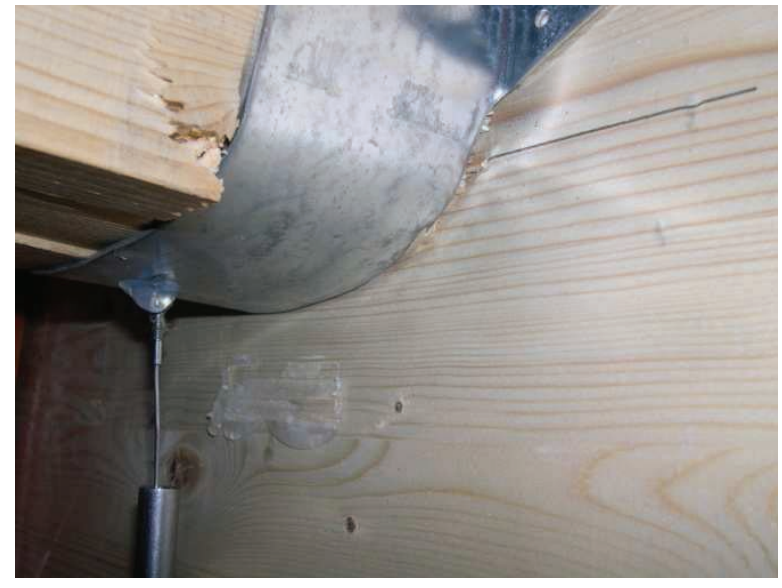

Fig. 13 Shearing of the member at the bottom of the 3D nailing plate.

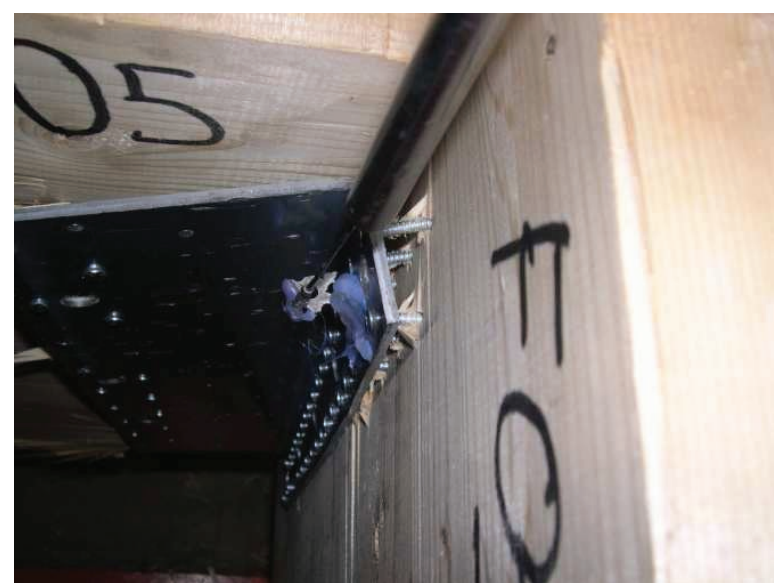

Fig. 14 Withdrawal of nail fasteners.

$\left(D_{2}-D_{1}\right)=9.4 \mathrm{~mm}$ mainly influenced by the compression of wood in the direction perpendicular to grain (hanger bottom), and the relative displacement $\left(D_{4}-D_{2}+D_{1}\right)=11.4 \mathrm{~mm}$ corresponding to the deformation at location of the load. This shows that the bending effect is not negligible.

The failure modes observed in the experimental tests are shown on Figs. 13 and 14. During the tests, the load $F$ (Fig. 6) is applied progressively. During the loading, the contact between the timber member and the bottom of the steel plate is developed. The steel plate develops a round shape around the beam member due to the interaction between the deformation of the steel plate in bending and tension (membrane effect) and the deformation of the timber member in local shear and compression. A local failure can be observed at the bottom of the timber member with the steel plate developing a large deformation (Fig. 13). The final stage of failure is reached by the withdrawal carrying capacity of the nails (Fig. 14). Then, a semi-rigid behaviour of the joint has to be considered to evaluate the applied moment at the 
end of the timber member (Fig. 14).

\section{SEMI-RIGID STIFFNESS IDENTIFI- CATION}

The joint, corresponding to node A (Fig. 15), is modeled by a semi-rigid behavior. The semi-rigidity is represented by two springs (translation and rotation). The translational spring represents the elastic support in the vertical direction (reaction force) and the rotational spring represents the rotation at the end of the connected beam (bending moment). The reaction force and the bending moment expressed as functions of the translation and the rotation in the joint are given by Eqs.(8). In these equations, $K_{y}$ and $K_{R}$ are the translational and the rotational stiffness modulus respectively, $v_{A}$ is the vertical slip and $\theta_{A}$ is the body rotation. It should be noted that $K_{y}$ and $K_{R}$ represent semirigidity caused by “TDNP"-support withdrawal and shear strengths.

$$
Y_{A}=K_{y} v_{A} ; \quad M_{A}=K_{R} \theta_{A}
$$

The objective of this section is to identify these stiffness modulus from experimental results, and, to introduce them in a numerical code, based on a finite element modeling. This allows studying and optimizing the stresses distribution on "TDNP" and members.

The timber properties may be regarded as transverse isotropy, which assumes identical properties in radial and tangential directions. This combined direction is referred to as perpendicular-to-grain while the longitudinal direction is referred to as parallel-tograin. The behavior of the timber beam with semirigid joints at its end (Fig. 15) is described considering the strain Energy $E_{p}$ (Eq. (9)). This energy includes the contribution of the bending moment $M(x)$ along the beam and the bending moment $\left(M_{A}\right)$ and the reaction force in the joints $\left(Y_{A}\right)$. The contributions of shear along the beam and the local compression of wood in the joints are neglected. In Eq.(9), $E$ is the Young modulus in the longitudinal direction and $I$ is

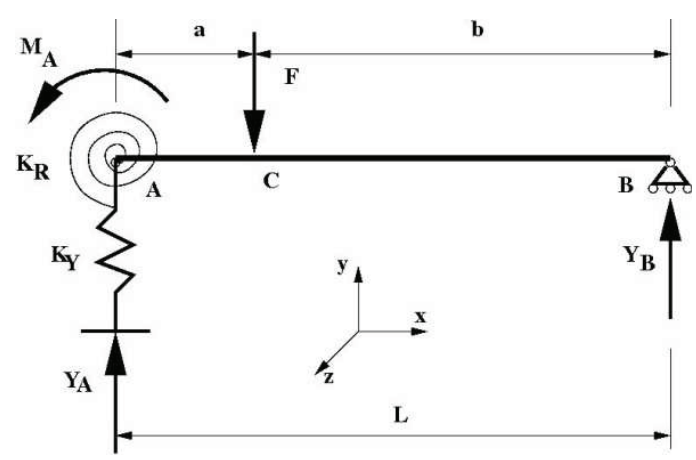

Fig. 15 Semi-Rigid beam model. the quadratic moment of the timber beam.

$$
E_{p}=\frac{1}{2} \int_{0}^{L} \frac{M^{2}(x)}{E I} d x+\frac{1}{2}\left(K_{y} v_{A}^{2}+K_{R} \theta_{A}^{2}\right)
$$

After replacing $M(x)$ by its expression and integrating on the member length $l$, the vector $R_{A}=$ $\left[\begin{array}{ll}Y_{A} & M_{A}\end{array}\right]^{T}$ is obtained by energy minimization: $v_{A}=$ $\partial E_{p} / \partial Y_{A} ; \theta_{A}=\partial E_{p} / \partial M_{A}$.

$$
R_{A}=\boldsymbol{A} F+B q_{A}
$$

with:

$$
\begin{gathered}
\boldsymbol{A}=\frac{(l-a)}{2 l^{3}}\left(\begin{array}{c}
\left(2 l^{2}+2 a l-a^{2}\right. \\
-a l(2 l-a)
\end{array}\right) ; \\
\boldsymbol{B}=\frac{3 E I}{2 l^{3}}\left(\begin{array}{cc}
1 & -l \\
-l & l^{2}
\end{array}\right)
\end{gathered}
$$

In Eq.(10), two parts are considered: $(\boldsymbol{A} F)$ concerns the rigid behavior and $\left(\boldsymbol{B} q_{A}\right)$ concerns the contribution of the nodal slip and the rotation at the end of the member. $F$ is a scalar representing the applied Load (Fig. 15). The geometrical characteristics of the member are the following: $A=e \times h, a=2 h, b=6 h$ and $L=8 h$, with $h=400 \mathrm{~mm}$ and $e=70 \mathrm{~mm}$. The axial Young modulus $E=E_{\mathrm{GL} 24 \mathrm{~h}}=11.6 \mathrm{kN} / \mathrm{mm}^{2}$. Considering these values, the numerical values of the matrices $\boldsymbol{A}$ and $\boldsymbol{B}$ are obtained (Eq.(12)).

$$
\begin{gathered}
\boldsymbol{A}=\left(\begin{array}{c}
0.91 \\
-524.0
\end{array}\right) ; \\
\boldsymbol{B}=\left(\begin{array}{cc}
2 \times 10^{-1} & -6.39 \times 10^{2} \\
-6.39 \times 10^{2} & 2.04 \times 10^{6}
\end{array}\right)
\end{gathered}
$$

From experimental results, graphical representations of the evolution of the moment $M_{A}$ versus the rotation $\theta_{A}$ (Fig. 16) and the evolution of the reaction $Y_{A}$ versus the displacement (slip) $v_{A}$ (Fig. 17) are shown. However, from the equations (10) and (11) and the Figs. 16 and 17, it can be observed the existence of linear relationships between $M_{A}$ and $\theta_{A}$ and between $Y_{A}$ and $v_{A}$. Hence, a linear relationship exists between $M_{A}$ and $Y_{A}$ (Fig. 18). The mean numerical

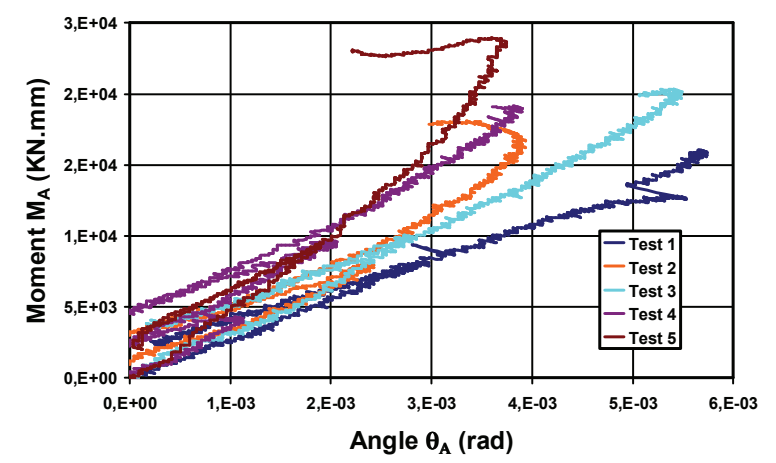

Fig. 16 Moment-rotation curves of the joint $\left(M_{A}-\theta_{A}\right)$. 


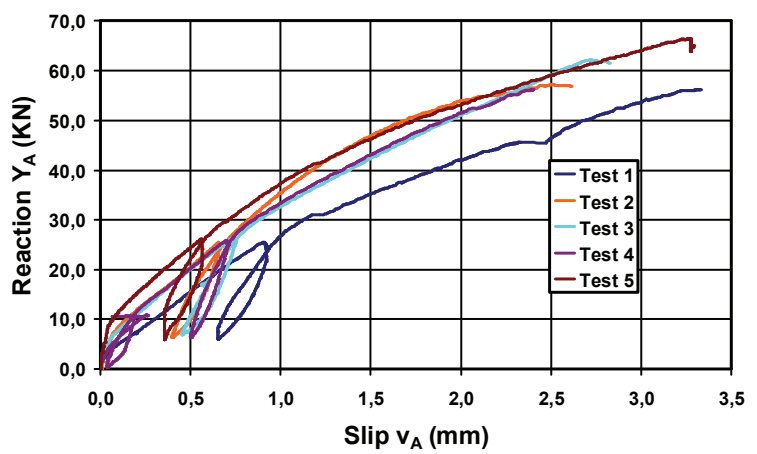

Fig. 17 Reaction ForceSlip curves of the joint $\left(Y_{A}-v_{A}\right)$.

Table 5 Statistical values.

\begin{tabular}{l|c|c|c}
\hline & $F_{\max }(\mathrm{kN})$ & $M_{A}(\mathrm{kNm})$ & $Y_{A}(\mathrm{kN})$ \\
\hline Estimate Mean Value & 67.0 & 27.6 & 58.8 \\
\hline SD Value & 3.8 & 2.6 & 3.5 \\
\hline Lower Mean Value & 58.8 & 22.0 & 51.3 \\
\hline Upper Mean Value & 75.1 & 33.1 & 66.4 \\
\hline
\end{tabular}

values are given in Eq.(13).

$$
\left\{\begin{array}{l}
M_{A}(\mathrm{~N} \cdot \mathrm{mm})=K_{R} \theta_{A}=3.02 \times 10^{9} \theta_{A} \\
Y_{A}(\mathrm{~N})=K_{y} v_{A}=2.76 \times 10^{4} v_{A}
\end{array}\right.
$$

where $\theta_{A}$ and $v_{A}$ are in (rad) and (mm) respectively.

In structural design, the joint is usually considered as perfectly rigid. However, as shown in Fig. 18 curves, in rigid case the eccentricity forces: is $e_{0}=M_{A} / Y_{A}=570 \mathrm{~mm}$, and, in semi-rigid behavior is $e_{1}=M_{A} / Y_{A}=410 \mathrm{~mm}$. Hence, the relative error between these assumptions is about $28 \%$.

The statistical values of $F_{\max }, M_{A}$ and $Y_{A}$ are summarized in Table 5.

Let $\mathrm{n}$ be the number of nail fasteners $(n \in \mathfrak{R})$ per side ensuring the rigid character to the plate-support joint, (in our case $n=18$ ). The maximum axial force is applied to the nail in the furthest position from the bottom of the plate. Its value is given by Eq.(14). In this equation, $y_{i},(i=1,2 n)$ is the distance between the nail fastener $i$ and the bottom of the plate, $y_{\max }$ is the distance of the furthest nail, and $M_{A}=Y_{A} \cdot e_{1}$. Eq.(14) is obtained considering a linear distribution of the forces on the nails proportional to the distance of each nail to the bottom of the plate. The bottom of the plate is thus considered as the centre of rotation of the joint with a constant axial stiffness for the nails. The reaction force is considered uniformly distributed on the nails (Eq.(15)).

$$
\begin{gathered}
F_{a x, E K}=\frac{1}{2} M_{A, E K}\left(y_{\max } / \sum_{i=1}^{n} y_{i}^{2}\right) ; \\
F_{v, E K}=\frac{Y_{A, E K}}{2 n}
\end{gathered}
$$

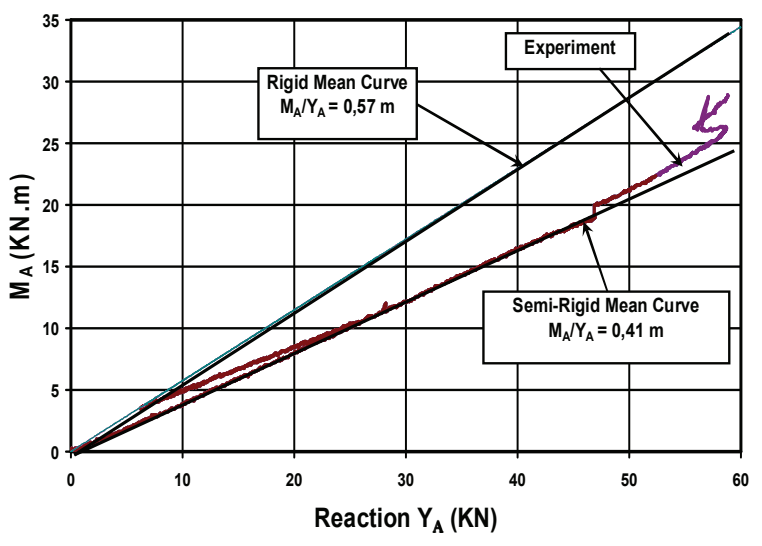

Fig. 18 Moment-reaction curves $\left(M_{A}-Y_{A}\right)$ curves.

Table 6 Design values.

\begin{tabular}{c|c|c|c}
\hline $\bar{Y}_{A}(\mathrm{kN})$ & $Y_{A 1, E k}(\mathrm{kN})$ & $Y_{A 2, E k}(\mathrm{kN})$ & $Y_{A 3, E k}(\mathrm{kN})$ \\
\hline 58.8 & 19.6 & 63.7 & 19.0 \\
\hline Relative Error & $67 \%$ & $8 \%$ & $68 \%$ \\
\hline
\end{tabular}

Considering that $Y_{A 1, E K}, Y_{A 2, E K}$ and $Y_{A 3, E K}$ are the reaction forces capacities for the three types of loading: axial force, shear force and combination of the axial and the shear forces, respectively. The timber design can be expressed by the equation (16), (17) and $(18)^{1)}$. In these equations, the used parameters are given hereafter: $\left(y_{\max } / \sum y_{i}^{2}\right)=3.75 \times 10^{-4} \mathrm{~mm}^{-1}$, $e_{1}=410 \mathrm{~mm}$ and $n=18$. The resistances $F_{a x, R k}$ and $F_{v, R k}$ are taken from Table 3. The maximum values of applied loads on the fasteners given by the equations (16-18) are summarized in Table 6.

$$
\begin{gathered}
F_{a x, E K} \leq F_{a x, R K} ; \\
\Rightarrow Y_{A 1, E K} \leq 2 F_{a x, R K}\left(\frac{\sum_{i=1}^{n} y_{i}^{2}}{e_{1} y_{\max }}\right) \\
F_{v, E K} \leq F_{v, R K} ; \Rightarrow Y_{A 2, E K} \leq 2 n F_{V, R K} \\
\Rightarrow\left(\frac{F_{a x, E K}}{F_{a x, R K}}\right)^{2}+\left(\frac{F_{V, E K}}{F_{V, R K}}\right)^{2} \leq 1 ; \\
\Rightarrow Y_{A 3, E K} \leq\left[\left(\frac{e_{1} y_{\max }}{2 F_{a x, R K} \sum_{i=1}^{n} y_{i}^{2}}\right)^{2}+\left(\frac{1}{2 n F_{V, R K}}\right)^{2}\right]^{-1 / 2}
\end{gathered}
$$

It can be observed that the value of shear capacity is closer to the average value given by the experiment with relative error of $8 \%$, and $\bar{Y}_{A \text {,inf }} \leq Y_{A 2, E k} \leq \bar{Y}_{A \text {,inf }}$ (Table 5).

Indeed, formulas (14) imply that the load applied to the joist is directly transmitted to the support member in perfect linear way through the nails. Also, the 


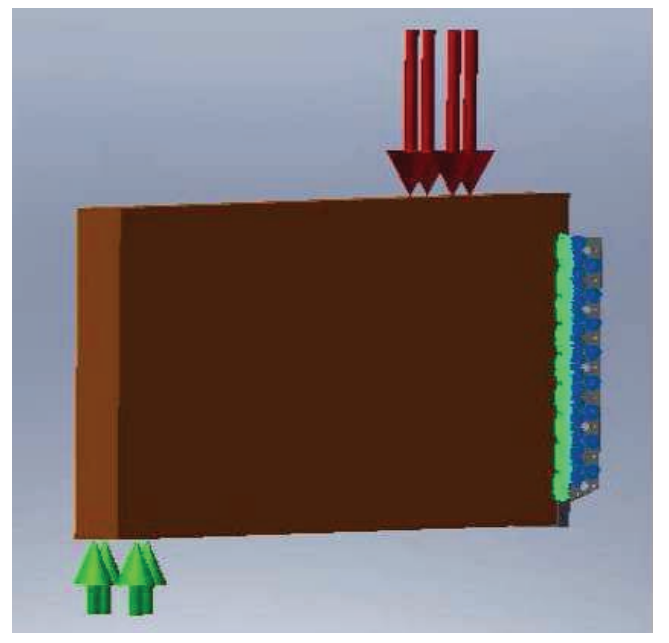

Fig. 19 FEM Modeling.

distribution of the moment effect among the nails is linear on the height of the hanger. In reality, this load distribution is influenced by behaviors of timber and by bottom of the metal plate deformations and contact-friction with support member. This is a complex non-linear mechanical behavior. To separate the different phenomena, it is necessary to carry out non expensive tests, based on numerical simulation to determine interaction parts of different components of joint.

\section{FINITE ELEMENT MODELING}

The joint including the timber, the hanger and the nails are modeled. The finite element model represents the timber member and the steel hanger through a cubic three dimensional elements (8 nodes) with elastic linear hypothesis. As a preliminary phase, the type of elements and the mesh density are validated on the basis of a timber beam in bending. The model used is shown in Fig. 19. The mechanical behaviors of nails are introduced in the form of bidirectional springs, where axial and transverse stiffness are obtained from the experimental results. Thus, using Eq.(13), the elementary stiffness of one nail $K_{x i}$ and $K_{y i}$ are obtained.

$$
K_{x i}=\frac{K_{R}}{2 \sum_{i=1}^{n} y_{i}^{2}}: K_{y i}=\frac{K_{y}}{2 n}
$$

The three dimensional nailing plates are made using galvanized mild steel. The mechanical characteristics of the steel are introduced in the finite element code "Cosmos": Young's modulus $E=230$ $\mathrm{GPa}$, Poisson's ratio $v=0.3$, and $f_{y}=250 \mathrm{MPa}$. The glulam member of resistance class GL24h is modeled using the following isotropic transverse mechanical properties: Young's modulus in the longitudinal di-

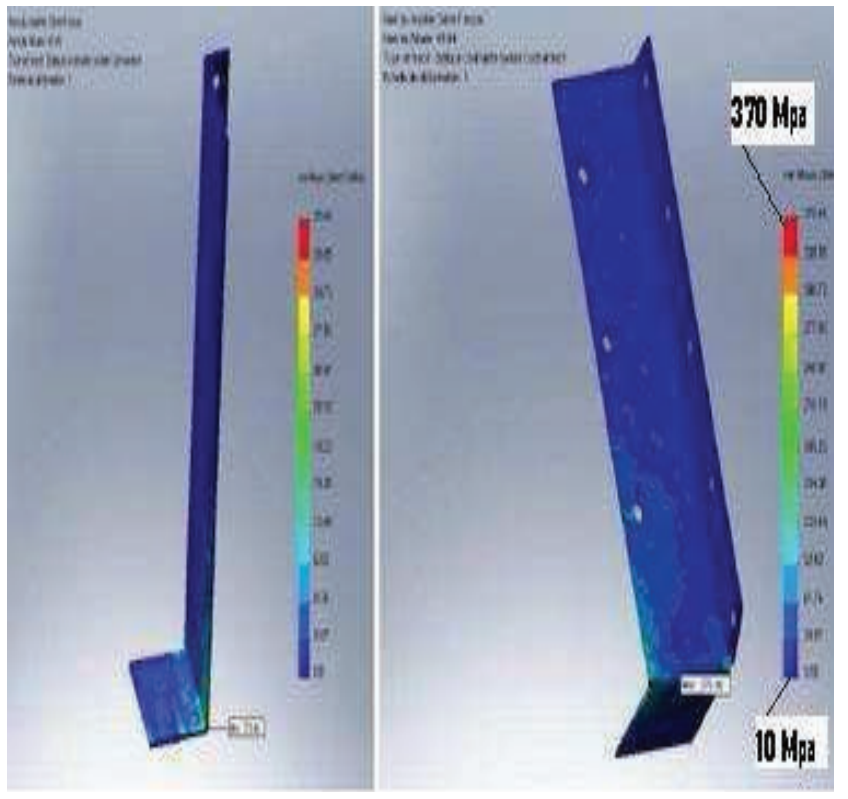

Fig. 20 Stresses distribution.

rection $\left(E_{0}=11600 \mathrm{MPa}\right)$ and in the transversal direction $\left(E_{90}=390 \mathrm{MPa}\right)$ and Poisson's ratio $v=0.2$. The measured mean value of the timber density $\rho_{m}$ is equal to $413 \mathrm{~kg} / \mathrm{m}^{3}$ for the beam support and 405 $\mathrm{kg} / \mathrm{m}^{3}$ for the main beam (supported beam).

The model takes into account the contact phenomenon between the timber member and the plate considering a linear behavior. Due to the symmetry, only half of the three dimensional metal plates is modeled. Nails are modeled using bidirectional linear springs with axial and lateral stiffness parameters given by Eq.(19). The contact at the bottom of the plate, between the member and the support, is represented by axial bilinear springs with stiffness parameter equal to the transverse Young's modulus " $E_{90}$ ". This modeling was carried out on the specimen with metal plate of the following geometry: height $H_{e}=332.5 \mathrm{~mm}$, thickness e $e=3 \mathrm{~mm}$ and depth $Z_{e}=100 \mathrm{~mm}$ (Fig. 1 (b)).

When the contact occurs, the results are obtained by iterative numerical procedure in terms of load $F$ value. Through the results of Fig. 20, the numerical stresses intensity map is drawn. We can show the influence on the contact zones.

In the numerical simulation, we can also control the vertical member and timber displacements. Indeed, in Fig. 21 and Fig. 22, are plotted displacement $D_{1}$ ("TDNP" slip) and $D_{2}$ (member slip) in terms of the applied load $F$ (Fig. 6), where, discontinuous curves drawn correspond to the experiment and those plotted continuously to numerical simulation.

With introduction of real mechanical behavior of nails, simulation allows to reproduce the real behavior of joint. Using the approach applied in this study, 


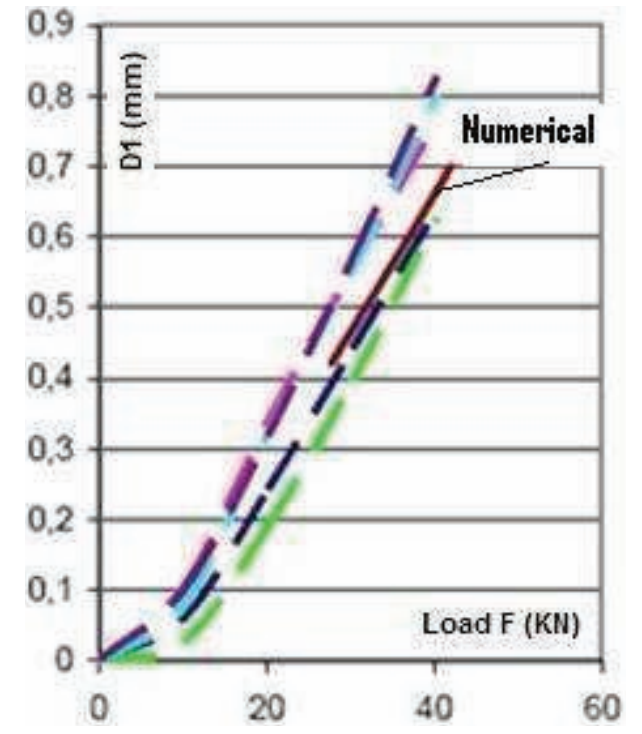

Fig. 21 Displacement $D_{1}(\mathrm{~mm})$ - Load $F(\mathrm{kN})$.

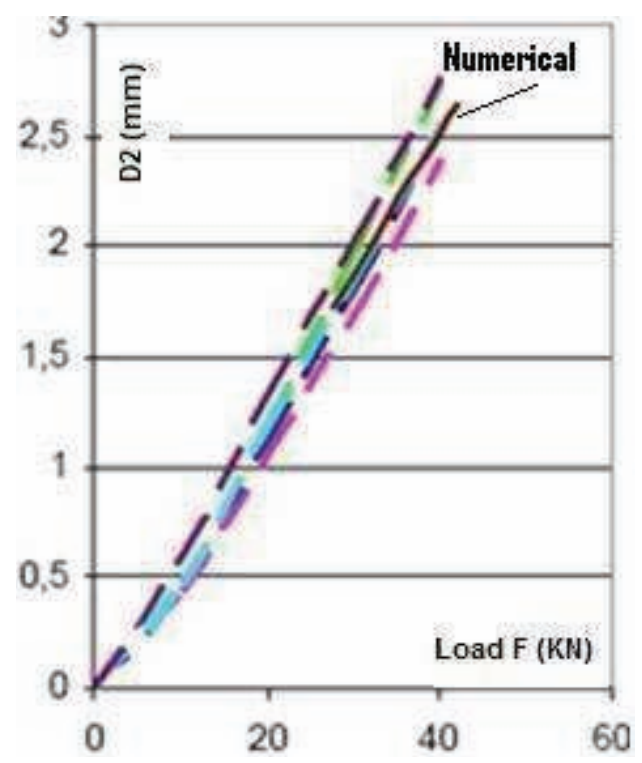

Fig. 22 Displacement $D_{2}(\mathrm{~mm})$ - Load $F(\mathrm{kN})$.

it is possible to analyze the behavior of a joint taking into account the behavior of the plate-support and the nails. This model has to be improved by the introduction of the non linear behavior of the materials to represent mainly the failure or postfailure modes observed during tests. This concerns mainly the compression perpendicular to grain and the shearing at the bottom of the timber member. With this development, it will realistic to optimize the whole system including the timber beams, the steel hangers and the nails.

\section{CONCLUSION}

This study provided a comprehensive approach to characterize member-to-member nailing metal plate joint with specific nails.

The study showed that the use of specific timber in member joint requires experiments characterization of withdrawal, shear and bending moment capacities. The results shown that the yield moment $M_{y, k}$ evaluated by design standard is not accurate and that the errors observed, between experiment and design, on the axial and transverse nails capacities $F_{a x, R E d}$ and $F_{v, R d}$ are close to $15 \%$ and $5 \%$ respectively.

The fourth section showed that the experimental strength capacity of joint is well above the predicted one. In the fifth section, the comparative study between calculated and experimental statistical results showed an error of $46 \%$ when the axial and the lateral behaviors are combined. However, it is possible to represent nail behavior by a pair of axial and transverse stiffness parameters and understand the overall member-to-member joint mechanism using "FEM" modeling.

With "FEM" modeling, using a mechanical bidirectional springs representing nail joint, allows, with the help of stress distribution card, a better localization of the high stress zones in the joint. Thus, it is possible to optimize the geometry of the joint members. Nevertheless, it should be noted that this study has been made under the assumption of linear behavior of the materials. The introduction of local non-linear contact and perpendicular compressive member behavior laws, will give the possibility of optimizing all joint members.

ACKNOWLEDGEMENT: The support of this work by Aginco-SAS Company, through scientific research program, is gratefully acknowledged.

\section{Appendix A NOMENCLATURE}

$M, N, V:$ External bending moment, Axial and Shear Forces;

$d, l_{p}:$ Nail diameter and length

$d_{h}, h_{t}:$ Nail head diameter and thickness

$e_{0}, e_{1}$ : Rigid and semi-rigid eccentricity values

$F_{v, R k}$ : Characteristic load-carrying capacity per shear plane per fastener

$F a x, R k$ : Characteristic withdrawal capacity of the fastener

$M_{y, R k}:$ Characteristic fastener yield moment

$f_{h, k}$ : Characteristic embedment strength in the timber member

$f_{u}, f_{y}$ : Tensile strength and characteristic yield strength of the wire

$t, t_{1}$ : Timber thickness, timber thickness per penetration depth

$H_{e}, e_{e}, Z_{e}$ : height, width and depth three-dimensional metal plate

"FEM" : Finite Element Method 
"TDNP": Three-Dimensional Nailing Plate

$F_{a x, R d}$ : Design value of axial withdrawal capacity of the fastener

$F_{v, R d}$ : Design shear force per shear plane of fastener

$\bar{X}, X_{\sigma}$ : Mean and standard deviation values of $X$

$\bar{X}_{\text {inf }}, \bar{X}_{\text {sup }}:$ Lower and upper estimate mean values of $X$

$L, h, e$ : length, height and thickness of member

$E, G$ : Young and Shear modulus

$A, I$ : Cross section and quadratic moment

$E_{0}, E_{90}$ : Parallel and perpendicular to grain elasticity modulus

$\rho_{k}, \rho$ : Characteristic and mean values timber density

$R_{m x, E K}$ : Characteristic load-carrying capacity of an axially loaded connection

$R_{m v, E K}$ : Characteristic load-carrying capacity of a shear loaded connection

$R_{m, E K}$ : Characteristic load-carrying capacity of an axially and shear loaded connection

"ESTD" : European STandarDs

\section{REFERENCES}

1) EN 1995-1-1: Eurocode 5: Design of timber structures. Part 1-1: General rules and rules for buildings. CEN/TC 250/SC5, 2004.

2) Kevarinmaki, A.: Behaviour of fasteners and glue-in rods produced from stainless steel, Proc. of the 37th CIB-W18 meeting, Edinburgh, United Kingdom, Paper 37-7-13, 2004.

3) Kevarinmaki, A.: Nails in spruce splitting sensitivity, end grain joints withdrawal strength, Proc. of the 38th CIB-W18m, Karlsruhe, Germany, paper 38-7-6, 2005.
4) Larsen, H. L. and Jensen, J. L.: Influence of semiridity of joints on the behaviour of timber structures, Prog. Struct. Engng. Mater., Vol. 2, No. 3, pp. 267277, 2000.

5) Foschi, R. O.: Analysis of wood diagrams and trusses. Part II: Truss-plate connections, Canadian Journal of Civil Engineering, Vol. 4, No. 3, pp. 353-362, 1977.

6) Branco, J. M., Cruz, P. J. S. and Piazza, M.: Experimental analysis of laterally loaded nailed timberto-concrete connections, Journal of Construction and building materials, Vol. 23, No. 1, pp. 400-410, 2009.

7) Blass, H. J. and Bejtka, I.: Screws with Continuous Threads in Timber Connections, Proceedings pro22, International RILEM Symposium on Joints in Timber Structures, Stuttgart, pp. 193-201, 2001.

8) Johansen, K. W.: Theory of Timber Connections, International Association of Bridge and Structural Engineering, Publication No. 9, pp. 249-262, Bern, Switzerland, 1949.

9) Chui, Y. H. and Li, Y.: Modeling Timber Moment Connection under Reversed Cyclic Loading, Journal of Structural Engineering, Vol. 131, No. 11, pp. 17571763, 2005.

10) Jorissen, A.: The stiffness of multiple bolted connections, Proc. of the 32th CIB-W18 meeting, Graz, Austria, paper 32-7-6, 1999.

11) Chen, C. C., Lu, C. A. and Lin, C. C.: Parametric study and design of rib-reinforced steel moment connections, Engineering Structures, Vol. 27, No. 5, pp. 699-708, 2005.

12) Blass, H. J., Bienhaus, A. and Kramer, V.: Effective bending capacity of dowel-type fasteners. In: Proceedings PRO 22, International RILEM symposium on joints in timber structures, pp. 71-80, 2001.

(Received April 30, 2009) 